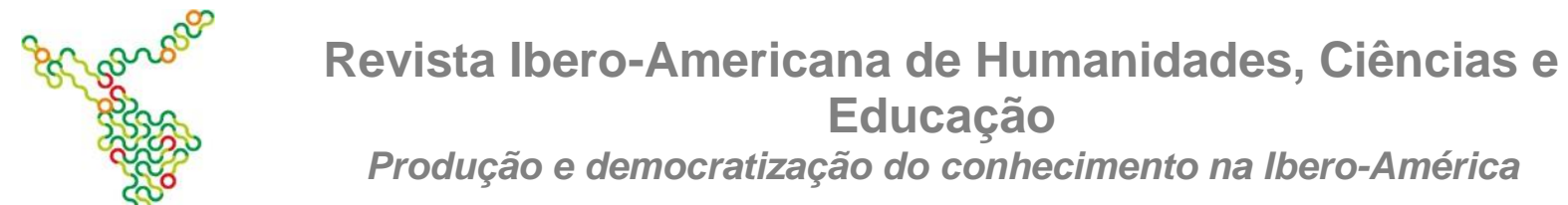

\title{
HABITAÇÃO EM FLORIANÓPOLIS: OS/AS TRABALHADORES/AS DA VILA OPERÁRIA HOEPCKE (1945-1960)
}

\author{
Jéssica Duarte de Souza ${ }^{1}$
}

\begin{abstract}
Resumo: O objetivo desse estudo é verificar as relações de trabalho e moradia ocorridas em Florianópolis entre os anos de 1945 a 1960. A pesquisa em andamento pretende verificar como ocorreram os modelos de políticas habitacionais na cidade, quem elas atingiam e que diálogos traçavam com o cenário nacional. Percebendo a moradia como um espaço importante de sociabilidade entre os(as) trabalhadores(as), mas também como uma política de extensão do controle da força de trabalho pelos patrões e Estado, esse trabalho buscou dar base empírica a essa relação com o estudo de uma vila operária da Companhia Hoepcke, empresa de diferentes ramos e com importância econômica e política da cidade. Analisando um Livro de Registro de Funcionários dessas fábricas e entrevistas de trabalhadores/as dos locais, foi possível revelar questões sobre o perfil desses(as) operários(as), como a hierarquia de trabalho nas fábricas, com os locais ocupados por descentes de imigrantes, mulheres, nacionais negros e brancos, e quem habitava a vila da empresa. Buscou-se estabelecer uma conexão entre a realidade desses(as) trab0alhadores(as), as condições de moradia na vila com as políticas de habitação ocorridas nesse período.
\end{abstract}

Palavras-chave: Trabalho, Moradia, Florianópolis.

Housing in Florianópolis: the workers of the working village Hoepcke (1945-1960)

Abstract: The objective of this study is to verify the relations of work and housing that took place in Florianópolis between the years of 1945 and 1960. The research in progress intends to verify how the models of housing policies occurred in the city, who they reached and that dialogues traced with the national scenario . By perceiving housing as an important space of sociability among workers, but also as a policy of extending labor force control by employers and the State, this work sought to provide an empirical basis for this relationship with the study of a working village

of the Company Hoepcke, company of different branches and with economic and political importance of the city. By analyzing an Employees' Record of these factories and interviews of local workers, it was possible to reveal questions about the profile of these workers, such as the hierarchy of factory work, with the locations occupied by descendants of immigrants , women, black and white nationals, and who inhabited the village of the company. It was sought to establish a connection between the reality of these workers, the living conditions in the village and the housing policies that occurred during this period..

Keywords: Work, Housing, Florianópolis.

\footnotetext{
${ }^{1}$ Mestranda no Programa de Pós-Graduação em História da Universidade Federal de Santa Catarina, Florianópolis, Brasil. Bolsista da Coordenação de Aperfeiçoamento de Pessoal de Nível Superior (CAPES).
} 


\section{Revista Ibero-Americana de Humanidades, Ciências e Educação \\ Produção e democratização do conhecimento na Ibero-América}

Florianópolis, apesar de ser a capital, não era a cidade mais populosa e com desenvolvimento econômico mais relevante do estado. Em 1950, sua população era de 67.630 habitantes, dos quais 23.223 eram eleitores (PELUSO JÚNIOR, 1991, p. 1). Era considerada uma cidade pobre em virtude da falta de estabelecimentos industriais, mecanismo valorizado no período como meio de desenvolvimento econômico (PAIVA, RIBEIRO, GRAEFF, 1952). Essa ausência pode ser verificada quando a dinâmica empregatícia do município é analisada. No levantamento do Anuário Estatístico de 1945, das 21 capitais arroladas, Florianópolis estava entre as três menos industrializadas, com 13 estabelecimentos industriais contando com 530 trabalhadores/as. No âmbito comercial, no mesmo levantamento, a cidade apresentava 43 comércios, somando 544 funcionários/as. Para o setor público, considerada a dinâmica empregatícia mais importante de Florianópolis a partir da década de 1930, a soma das atividades governamentais, em 1940, correspondia a $32,5 \%$ da oferta de empregos do município, em uma população ativa de 7.745 pessoas (PELUSO JÚNIOR, 1991, p. 7).

A capital era uma cidade quase sem industrias, que vivia de um pequeno comércio e muito dependente dos empregos públicos oferecidos pelo Estado. Além dessas ocupações registradas, haviam muitos trabalhadores/as informais, sem vínculo empregatício, vivendo de comércio de artesanatos, gêneros alimentícios e pesca artesanal. Essa parcela não possuía nenhuma segurança sobre o seu amanhã. Porém, não havia uma nítida fronteira entre esses dois grupos de trabalhadores formais e informais, que em muitos casos compartilhavam laços familiares, culturais, ou mesmo transitavam entre as duas situações de classe. Também uma prática comum em Florianópolis era a complementação da renda do trabalho formal, aquele registrado, com a pesca, pequenas hortas e venda de animais, principalmente nas regiões mais periféricas do perímetro central. Desse modo, o rural e o urbano entrecruzavam-se em Florianópolis, algo que foi enfraquecendo na medida que a urbanização e o mercado imobiliário se expandiam (AREND, LOHN, 2013, p. 55)

Diante desse cenário, uma empresa destacava-se por ser o único estabelecimento de envergadura do setor produtivo na cidade. A Carlos Hoepcke S.A foi fundadapelo imigrante alemão Carl Hoepcke na última década do século XIX e desde sua criação já atuava em diferentes ramos econômicos. A Companhia Hoepcke, como era chamada logo após sua criação, ainda nas primeiras décadas do século XX possuía casas comerciais, cooperativas de crédito, Companhia de Navegação, Estaleiro, Oficina mecânica e as fábricas de Pontas (pregos) Rita Maria (1896), de Gelo (1897) e Rendas e Bordados (1913). Além dos empreendimentos em Florianópolis a empresa tinha filiais de suas casas comerciais em outras regiões catarinenses (MÜLLER, 2007). No início século XX, os 


\section{Revista Ibero-Americana de Humanidades, Ciências e Educação \\ Produção e democratização do conhecimento na Ibero-América}

estabelecimentos da empresa faziam saltar o número de industrias e de operários(as) do município florianopolitano, que em comparação com as demais cidades do estado, ocupava o terceiro lugar na distribuição de estabelecimentos industriais por município (BOSLLE, 1988, P. 47). Ao longo do século XX o empreendimento manteve-se em progressão econômica e destaque social. Em 1940 Aderbal Ramos da Silva chega à presidência da empresa. Ramos da Silva era a principal figura política do PSD (Partido Social Democrático) na capital e integrante de uma das maiores oligarquias catarinense: os Ramos. Nesse sentido, pólos de influência política e econômica juntavam-se na capital.

Para a realidade econômica de Florianópolis, o número da mão de obra movimentada pelas fábricas da Companhia têm grande significado. Essa circunstância fez com que surgisse uma pequena vila operária nas imediações das três fábricas que estavam situadas no bairro Rita Maria, próximo ao centro da cidade. A criação da vila ocorreu poucos anos após a fundação da Fábrica de Pontas Rita Maria (1896) e ficava na rua posteriormente chamada de Rua Hoepcke. Nesse momento, o local em que a vila se situava não era o mais apropriado para habitações, a rua tinha como vizinhos um cemitério e um forno incinerador de lixo. A região tinha poucas habitações por ser bastante íngreme e rochosa, mas a medida em que a cidade foi crescendo e principalmente com a inauguração da ponte Hercílio Luz, em maio de 1926, a vila foi sendo incorporada à cidade (VEIGA, 2010, p. 280). Desse modo, em 1945, início do período que essa pesquisa analisa, a rua Hoepcke fazia parte do distrito central e estava próxima ao único acesso terrestre da Ilha com o continente, já não sendo mais um local tão facilmente habitado por trabalhadores(as).

A urbanização de Florianópolis se deu de maneira peculiar, apesar de ser uma cidade com baixa densidade demográfica, as fronteiras de expansão urbana limitavam-se a baía norte e o Morro da Cruz, sendo o restante da Ilha composto por pequenas povoações isoladas e de difícil acesso (LOHN, 2002, p. 81). Mesmo com espaços vacantes, a precariedade de acesso ao interior da Ilha impedia que a população pobre, que matinha seu sustento no centro comercial, ocupasse essas regiões. Desse modo, residir na vila operária da empresa, apesar de todos os problemas que veremos a seguir, estava carregado de um significado importante, dentro do contexto urbano de Florianópolis.

Portanto, quais os locais ocupados pela população mais pobres e quais eram suas demandas? Na tentativa de responder essa questão foram analisados Ofícios da Prefeitura de 


\section{Revista Ibero-Americana de Humanidades, Ciências e Educação \\ Produção e democratização do conhecimento na Ibero-América}

Florianópolis para a Câmara Estadual de Santa Catarina. Entre esses documentos a demanda por estrutura básica de urbanização, como falta de água, energia elétrica, acesso básico a saúde e pavimentação de ruas estavam muito presentes. Os relatos analisados na documentação demonstram que os problemas citados apresentavam-se em lugares demarcados, geralmente às margem da parte central, como o Estreito e Saco dos Limões. Essa espacialização faz sentido devido a necessidade de proximidade com o centro, mas a impossibilidade de residir naquela região por causa dos elevados preços de aluguéis e a constante desapropriação de populares no local. Nesse sentido, essa margens próximas ao centro tornavam-se alvo para habitação, já que não possuíam estruturas básicas acabavam tornam- se mais baratas e consequentemente, habitadas pela população pobre geralmente trabalhadora do centro da cidade.

O encarecimento do distrito central da cidade vinha ocorrendo desde 1920, com o calçamento e abertura de ruas. Mas em 1940 essas mudanças ganham outro volume, prédios passam a ser construídos destinados a escritórios e/ou hotéis e as transformações nas feições das ruas do centro acontecem com mais intensidade e rapidez. Essas obras faziam parte de um momento de mudanças socioeconômicas que ocorreram após 1945 e que impactaram Florianópolis. Era caracterizado por uma longa transição, nas décadas seguintes, de um paulatino abandono de atividades produtivas e importantes ramos comerciais pelo investimento no mercado imobiliário (AREND, LOHN, 2013, p. 35). No estudo de Carina da Cruz (2008), em que investigou os balanços financeiros da principal empresa do município, a Carlos Hoepcke, constatou que entre 1942 e 1945 o valor de imóveis e propriedades no ativo imobilizado praticamente dobrou. Mesmo atuando em diferentes setores produtivos, a empresa deslocou investimentos para o mercado imobiliário, que segundo a autora, era uma tendência que apontava para a "falta de perspectivas nas atividades produtivas de Florianópolis". O investimento imobiliário se dava ao mesmo tempo em que ocorria o desmembramento de grandes áreas de chácaras localizadas nas imediações do perímetro urbano para a formação de loteamentos (a maior delas, com cerca de 20 mil metros quadrados, pertencia à família da Carlos Hoepcke).

O espaço da cidade estava em disputa, a distribuição espacial obedecia às divisões de classe e isso indicou um constante processo de afirmação de determinados valores e finalidades para as políticas urbanas implementadas. O projeto político fomentado nesse período como principal 


\section{Revista Ibero-Americana de Humanidades, Ciências e Educação \\ Produção e democratização do conhecimento na Ibero-América}

alternativa para superação do atraso econômico de Florianópolis teve implicações direta na fragmentação e manutenção do espaço como clivagem social: o turismo. Assim, a exploração imobiliária assumiu ares de estratégia para ativação da economia da cidade e ganhou respaldo social. O discurso de modernizar os espaços para a recepção dos visitantes legitimou os projetos e planos urbanísticos com intenções de manter intacta a distribuição de poderes e riquezas na cidade (LOHN, 2002).

Nesse contexto em que a exploração imobiliária ganhava corpo o poder público criou ferramentas institucionais que pudessem auxiliar a capacidade de gestão desse processo. Para pensar o planejamento urbano a Prefeitura contratou um Escritório de Urbanismo de Porto Alegre para a criação de um Plano Diretor, que promovesse a urbanização. O primeiro Plano Diretor da capital catarinense foi elaborado por dois arquitetos (Demétrio Ribeiro e Edgar Albuquerque Graeff) e um engenheiro urbanista (Edvaldo Ruy Pereira Paiva) em 1952. A versão final do Plano, em 1955, foi transformada em lei municipal, mas poucas das propostas chegaram a ser implementadas (LOHN, 2002).

O Plano Diretor salientou a importância do resgate da função portuária da cidade. O caminho para o crescimento econômico seria o desassoreamento entre a Ilha e o continente, permitindo a entrada de grandes navios e a necessidade da construção de um grande porto na região continental. Sem essas condições Florianópolis continuaria com suas feições de atraso e com pouca articulação com a parte continental do município, um dinamismo essencial para o desenvolvimento urbano.

A cidade enfrentava o problema de muitas zonas vazias entre as povoações e esses problemas estruturais faziam com que apresentasse grande dispersão urbana. Essa condição desfavorecia a produtividade do trabalho e despendia com obras de expansão viária e de transporte. Em 1946, pouco mais de 25\% da área urbana florianopolitana era “constituída por terrenos vacantes", situação diretamente relacionada à especulação com a propriedade imobiliária (DIAS, 1948, p. 60-61 apud AREND, LOHN, 2013, p. 50).

Nesse quadro, não é de se estranhar a habitação como um problema fundamental da cidade. Através dos ofícios conseguimos apreender um pouco de como a temática estava chegando no poder público. Em um documento de 1955, redigido pelo prefeito 


\section{Revista Ibero-Americana de Humanidades, Ciências e Educação \\ Produção e democratização do conhecimento na Ibero-América}

recém eleito (1954) Osmar Cunha, do PSD, a prefeitura solicitava a doação de terreno estatal para a construção de casas populares. Nesse

documento ele enfatizou o problema da fragmentação da urbe e do processo de formação de"malocas" nos arredores da cidade:

E o resultado é a existência de grande número de núcleos esparsos da população, na cidade e arredores, localizados, predominantemente, nos morros, vivendo em miseráveis casebres, na mais perniciosa promiscuidade e desoladora condição de conforto e higiene. (FLORIANÓPOLIS, 1955)

Conforme demonstrado no excerto do documento do prefeito Osmar Cunha, havia uma preocupação com as ocupações dos morros, que também configuravam um dos locais de população de baixa renda, mas esses eram ainda mais precarizados que o Estreito e Saco dos Limões, citados anteriormente. É provável que o projeto do prefeito era que as pessoas que moravam nos morros ocupassem as casas populares que queria construir em sua gestão, aplicando assim a lei municipal 105 de 1951. Provavelmente essa era uma tentativa de conciliar a necessidade de um modelo urbano para a cidade, em que os morros não faziam parte com o atendimento das demandas populacionais, causando mais popularidade com a sua gestão e possíveis futuros eleitores para o seu partido.

Sob a referida lei, ela foi criada em 1951, pelo prefeito da UDN, Paulo Fontes. Entre os artigos estabelecidos pela legislação, estavam a destinação de 3\% da receita municipal para a construção de casas populares, que deveriam ocorrer preferencialmente em terrenos suburbanos, sua venda seria destinada apenas para quem não possuísse algum imóvel, a preço de custo e com o pagamento a vista ou em parcelas mensais com o prazo máximo de dez anos, sem juros ${ }^{3}$. Até o momento não há nenhuma indicação que essa doação de fato ocorreu e que a legislação foi colocada em prática, mas é importante pensar que o debate estava ocorrendo em nível municipal, e que não pôde passar ao largo das preocupações, pelo menos de algum modo, dos governante.

Porém, apesar da referida lei, não foi encontrada nenhuma informação sobre a execução dessas casas. Desse modo, os problemas gerados pela urbanização e crescente processo de exploração imobiliária são agravados pela quase nula responsabilidade dos poderes públicos com habitação popular. Como únicos responsáveis pela concessão e manutenção da moradia, estratégias de solidariedade como a construção coletiva de 


\section{Revista Ibero-Americana de Humanidades, Ciências e Educação Produção e democratização do conhecimento na Ibero-América}

casas, foram traçadas entre os/as trabalhadores/as. Seu Higino, funcionário de uma madeireira do município, contou em sua entrevista como ocorria o processo de construção das casas dos trabalhadores do local. Quando um dos seus colegas ia construir sua casa, um grupo de 10 a 15 trabalhadores da madeireira deslocava-se até o local para auxiliar na construção. Essas atividades eram sempre exercidas nos finais de semana, momento que em tese seria destinado ao descanso e lazer.

Desse modo, quais eram os locais que os(as) trabalhadores(as) da Companhia Hoepcke se estabeleciam na cidade? Visando compreender essa questão esse artigo analisou um livro de Registro de Funcionários que compilava trabalhadores(as) de duas das fábricas da empresa, sendo elas: Fábricas de Pontas e Fábrica de Gelos. Esse livro foi pesquisado no Instituto Carl Hoepcke e foi utilizado na empresa entre os anos de 1945 a 1960, aproximadamente. As informações contidas no livro são: número da carteira de trabalho, nome do(a) trabalhador(a), data de admissão, data e local de nascimento, local de residência, salário, cargo, informações de retiradas de férias e de acidentes de trabalho, além de, em quase todas as fichar, conter uma foto $3 \times 4$ do(a) funcionário(a).

São ao todo 144 fichas, 84 de homens e 60 de mulheres. Porém, algumas dessas fichas pertenciam ao mesmo trabalhador(a), por ter sido contratado e dispensado(a) mais de uma vez nas fábricas. Desse modo, entre os homens são 13 fichas e as mulheres 28 fichas que pertenciam ao um trabalhador(a) já admitido anteriormente pela empresa, tirando as fichas duplicadas do mesmo funcionário(a) contratado novamente, são 71 homens e 32 mulheres registrados no livro.

Como o recorte desse estudo está centrado na habitação, serão analisadas apenas as informações do local de moradia desses empregados(as). Para fins didáticos, foi separado o grupo masculino e feminino. Começaremos pelos homens, entre as 71 fichas de diferentes homens, 7 delas não informava a residência, dos 64 restantes o maior número morava na região continental. Trinta operários tinham como local de moradia principalmente o bairro Estreito, 23 situavam-se no distrito central e 11 nas margens periféricas desse distrito, em especial próximos ao maciço do Morro da Cruz. Dos 23 que moravam na parte mais urbanizadas, 3 eram moradores da vila operária. Desses 3 funcionários, 2 tinham data de admissão superior a 20 anos e 1 figurava entre os melhores remunerados do livro, esse ficou na empresa até se aposentar, conforme consta em sua 


\section{Revista Ibero-Americana de Humanidades, Ciências e Educação Produção e democratização do conhecimento na Ibero-América}

ficha. O que tinha em comum entre os três era sua função: oficial das máquinas.

Os estudos sobre vilas operárias demonstram que os critérios para locação de uma casa nas vilas tinham semelhanças. Uma família numerosa e mão-de-obra com alguma qualificação geralmente estavam associados aos requisitos à locação da casa. Para as empresas era importante ter próximo ao local de trabalho funcionários que soubessem resolver possíveis problemas com a produção e famílias extensas proporcionavam mãode-obra disponível mais facilmente (BLAY, 1985,p. 175).

Nesse sentido, os 3 trabalhadores operadores de máquinas eram figuras importantes na produção, a qualificação da mão de obra pode ter sido o critério de serem moradores da vila. O caso das trabalhadoras, pelo foto de serem temporárias, é provável que outros familiares trabalhassem nas fábricas e elas eram chamadas em períodos de maior produção.

A situação nas vilas operárias criava um vínculo entre contrato de trabalho e moradia, causando dupla instabilidade aos operários(as) e sua família. Essa condição podia reprimir as expressões de reivindicação e insatisfação desses(as) trabalhadores(as). José Sérgio Lopes (1988, p. 119) chama atenção para esse processo de interiorização da dominação por parte dos(as) operários(as) residentes nas vilas. Segundo o autor, ao focar exclusivamente no ponto da dominação, o papel da casa como aspecto importante dessa legitimação é negligenciado. Outras circunstâncias precisam ser analisadas para compreender a realidade do(a) trabalhador(a), como o valor de aluguel mais acessível, a proximidade do local de trabalho e manutenção da vila. O significado da moradia não se restringe ao econômico; esses locais estão permeados de laços de solidariedade, de conflitos e de sociabilidade. O caso da vila da empresa Carlos Hoepcke não se enquadra no padrão mais clássico de vila operária isolada, com dependência quase total da fábrica, os(as) funcionários(as) tinham acesso à outras dinâmicas empregatícias. Essas pessoas residiam no centro dacidade, com aluguel acessível e próximo ao seu local de trabalho. Isso significava ter acesso a alguma infraestrutura e não levar horas no caminho de casa ao serviço. Ao meio das políticas urbanas e encarecimento de aluguéis da região central de Florianópolis, residir no centro da cidade acarretava um valor simbólico. Residir na vila operária não era apenas estar submetido ao controle patronal, são muitos aspectos que poderiam se apresentar nessa relação. 


\section{Revista Ibero-Americana de Humanidades, Ciências e Educação \\ Produção e democratização do conhecimento na lbero-América}

Porém, conforme vimos através da amostra do Livro de Registro de Funcionários, a maioria dos(as) trabalhadores(as) residiam na parte continental da cidade, o bairro Estreito, e uma outra parcela em regiões periféricas ao distrito central. Para tentar elucidar as condições que essas pessoas passavam, nas entrevistas do Laboratório de História Oral da UFSC duas trabalhadoras da empresa relataram seus trajetos de casa ao trabalho. Uma delas, funcionária da Fábrica de Rendas e Bordados, residia no bairro Saco dos Limões, local relativamente próximo do centro de Florianópolis, porém, devido aos escassos horários de ônibus da linha que faria esse trajeto, precisava caminhar até o local de serviço todos os dias. Segundo seu relato, levava quase duas horas para chegar ao trabalho ${ }^{5}$ O outro caso, também trabalhadora da Fábrica de Rendas e Bordados e moradora do bairro Estreito, queixou-se da falta de transporte público na cidade. Não havia ônibus do seu bairro para o centro, apesar de a distância ser mais próxima do que o caso anterior, a exfuncionária da fábrica de pregos contou que em dias de chuva era inevitável se molhar, tendo que muitas vezes permanecer com a roupa molhada durante todo o dia de trabalho.

Desse modo, percebemos as dissonâncias entre um projeto de desenvolvimento urbano pautado no turismo e que negligenciava os próprios moradores. Esse pequeno estudo demonstra empiricamente onde as pessoas que trabalhavam na região central da cidade moravam e os problemas urbanos que enfrentavam. Em Florianópolis as questões de espacialização das desigualdades sociais estavam presentes e não ancoradas em uma lógica de produção, mas de uma capitalização do solo. Os projetos políticos de Florianópolis para a urbe, sempre mantendo os privilégios das elites locais, não pautaramse na dinâmica da industrialização, mas em um projeto do turismo.

\section{Referências}

AREND, S. M. F; LOHN, R. L. Estado e populações pobres no Brasil: a espacialização da desigualdade social em Florianópolis - SC (décadas de 1930-1950). Geosul, Florianópolis, v. 28, n. 56, p 33-64, jul./dez. 2013.

ABREU, Adélia Vieira. Trabalho da Fábrica de Rendas e Bordados Hoepcke de 1945-1950. [ago, 2002]. Entrevistadora: Maria das Graças Santos Luiz Brightwell. Laboratório de História Oral - UFSC.

SILVA, Zulma Rosa. Trabalho operário na Fábrica de Rendas e Bordados Hoepcke. [jun, 2003]. Entrevistadora: Raquel Bertoncini Filomeno. Laboratório de História Oral UFSC. 


\section{Revista Ibero-Americana de Humanidades, Ciências e Educação \\ Produção e democratização do conhecimento na Ibero-América}

BLAY, Eva Alterman. Eu não tenho onde morar: vilas operarias na cidade de São Paulo. São Paulo: Nobel, 1985.

BOSSLE, Ondina Pereira. História da industrialização catarinense: das origens a integração no desenvolvimento brasileiro. 2. ed. Florianópolis: CNI/FIESC, 1988.

CRUZ, Carina Martins da. A contribuição de alemães e descendentes para a formação sócio- espacial catarinense: o caso da região metropolitana de Florianópolis (SC). $206 \mathrm{f}$. Dissertação (Mestrado em Geografia). Universidade Federal de Santa Catarina, Florianópolis, 2008.

LOHN, Reinaldo Lindolfo. Pontes para o futuro: relação de poder e cultura urbana, Florianópolis, 1950 a 1970. 2002. 442 f. Tese (Doutorado em História) - Universidade Federal do Rio Grande do Sul, Instituto de Filosofia e Ciências Humanas, Porto Alegre, 2002.

LOPES, Jose Sergio Leite. A tecelagem dos conflitos de classe na 'cidade das chaminés'. São Paulo: Marco Zero; [Brasília]: Ed. UnB, 1988.

MÜLlER, Max José. Carl Hoepcke: estruturador do desenvolvimento catarinense. Florianópolis: Insular, 2007.

PAIVA, Edvaldo; RIBEIRO, Demetrio; GRAEFF, Edgar. Florianopolis: Plano Diretor (1952). 1952.

PELUSO JÚNIOR, Victor Antônio. O crescimento populacional de Florianópolis e suas repercussões no plano e na estrutura da cidade. In:_. Estudos de Geografia Urbana de Santa Catarina. Florianópolis: Editora da UFSC; Secretaria do Estado da Cultura e do Esporte.

VEIGA, Eliane Veras da. Florianópolis: memória urbana. 3. ed. rev. ampl. Florianópolis: Fundação Franklin Cascaes, 2010. 